\title{
KUALITAS LAYANAN DAN CITRA LEMBAGA TERHADAP WORD OF MOUTH MAHASISWA STAHN GDE PUDJA MATARAM
}

\author{
I Made Ngurah Oka Mahardika \\ Sekolah Tinggi Agama Hindu Negeri Gde Pudja Mataram \\ Email korespondensi: mahardikaind@gmail.com
}

\begin{abstract}
The competition between universities to get new students makes universities innovate in marketing strategy. This also applies to Sekolah Tinggi Agama Hindu Negeri (STAHN) Gde Pudja Mataram, a State Religious College under the Ministry of Religion continues to improve the service quality and company image so that students tell positive things to the community. This research used is quantitative method by taking 84 respondents of STAHN Gde Pudja Mataram bachelor students. The sampling technique uses accidental random sampling analyzed with SPSS 23 tools. The results of the analysis show that service quality has a positive but not significant effect on word of mouth. Then, the company image had a positive and significant effect on the word of mouth of STAHN Gde Pudja Mataram students. Therefore, STAHN Gde Pudja Mataram has to keep maintain the service quality and company image to the students so that they can raise the positive information by word of mouth to society.
\end{abstract}

Keywords: Service quality, Company Image, Word of Mouth

\section{A. PENDAHULUAN}

Perguruan Tinggi Keagamaan Negeri (PTKN) merupakan lembaga pendidikan tinggi yang didirikan oleh pemerintah. Saat ini, persaingan antar lembaga pendidikan tinggi semakin pesat. Kondisi ini berimbas pada PTKN terdorong untuk meningkatkan kuantitas dan kualitas mahasiswanya. PTKN terus berupaya meningkatkan kualitas layanan dan citra lembaga agar tetap eksis di era persaingan industri yang sangat ketat. Pertimbangan penting yang sangat diperhatikan oleh pengguna jasa pendidikan dalam memilih lembaga pendidikan tinggi adalah tersedianya layanan yang berkualitas dan optimal, kualitas pendidikan yang bagus dan tersedianya jaringan dalam menyerap lulusan (Saktiani, 2015).

Dalam pengambilan keputusan dalam memilih PTKN calon mahasiswa akan memperhatikan kualitas layanan yang diberikan dan citra dari lembaga. Menurut Anita dan Rahanatha (2015) menyatakan bahwa kualitas layanan berpengaruh positif dan signifikan terhadap word of mouth. Kualitas layanan penting diperhatikan untuk mendapat profitabilitas lembaga. Lembaga pendidikan yang berorientasi pada service business akan selalu memberikan pelayanan yang berkualitas bagi penggunanya. Kemudian, menurut Bayupratama (2017) citra lembaga berpengaruh positif dan signifikan terhadap word of mouth. 
Meningkatkan citra lembaga akan memberikan dampak penyebarluasan informasi yang positif yang dilakukan oleh pengguna jasa pendidikan kepada masyarakat luas. Penyebaran informasi yang positif secara luas merupakan keuntungan jangka panjang bagi lembaga karena dapat menekan biaya promosi (Mahardika, et al., 2018).

Citra lembaga tidak dapat diciptakan layaknya menciptakan barang dan jasa. Citra lembaga dapat terbentuk dari proses panjang dalam meningkatkan dan mempertahankan layanan yang berkualitas. Putra, et al., (2015) menyatakan bahwa citra lembaga merupakan persepsi dari konsumen terhadap lembaga yang direkam oleh memori konsumen sebagai filter yang dapat mempengaruhi persepsi konsumen terhadap lembaga. Citra lembaga yang baik akan berdampak pada kemauan pengguna jasa pendidikan untuk menceritakan hal-hal yang baik pula. Meningkatkan citra lembaga dilakukan dengan memberikan pelayan yang baik, peningkatan inovasi pelayanan, dan pengingkatan kualitas lulusannya.

Sekolah Tinggi Agama Hindu Negeri (STAHN) Gde Pudja Mataram sebagai salah satu PTKN di Kota Mataram terus berbenah dalam rangka peningkatan kualitas dan kuantitas mahasiswa. Sebagai lembaga penyedia jasa pendidikan STAHN Gde Pudja terus berbenah dalam kegiatan operasionalnya. Mahasiswa sebagai stakeholder menjadi asset yang dapat digunakan untuk meningkatkan citra lembaga atas terselenggaranya layanan prima. Penting bagi lembaga untuk terus meningkatkan citra lembaga melalui kualitas pendidikan yang ditawarkan yang secara langsung dapat meningkatkan kepuasan stakeholder. STAHN Gde Pudja Mataram berorientasi pada penciptaan lulusan yang siap pakai, hal tersebut sejalan dengan kebutuhan mahasiswa yang berharap nantinya dapat memenuhi kebutuhan pasar akan tenaga kerja yang kompeten.

Berbagai penelitian telah dilakukan untuk menguji hubungan kualitas layanan terhadap word of mouth. Penelitian yang dilakukan oleh Nuryanto, (2012) dalam penelitian yang berjudul kualitas layanan dan positive word of mouth menemukan bahwa kualitas layanan berpengaruh positif dan signifikan terhadap word of mouth pada siswa SMA St. Louis Semarang. Sedangkan, penelitian yang dilakukan oleh Ye, et al., (2011) menyatakan bahwa service quality tidak memiliki efek yang signifikan terhadap word of mouth pada perusahaan telekomunikasi di Cina.

Selanjutnya, penelitian yang dilakukan dalam rangka menguji hubungan citra lembaga terhadap word of mouth juga masih menemukan hasil yang berbeda. Penelitian yang dilakukan Putra, et al., (2015) mengemukakan bahwa citra lembaga memberikan pengaruh yang positif dan signifikan terhadap word of mouth pada Bank BPD Bali di Denpasar. Namun, penelitian 
berbeda dikemukakan oleh Sriwidodo and Ernawati (2014) yang menemukan bahwa citra Pasar Jumat Karanganyar tidak memiliki pengaruh yang signifikan terhadap word of mouth positif pengunjung Pasar Jumat Karanganyar.

Berdasarkan hasil penelitian tersebut masih terdapat hasil temuan berbeda (research gap) antara variabel kualitas layanan terhadap word of mouth, dan variabel citra lembaga dengan word of mouth dari berbagai penelitian. Berdasarkan pemaparan latar belakang diatas posisi penelitian ini adalah untuk mengkonfirmasi dan mengisi research gap yang tersedia antara variable kualitas layanan, citra lembaga terhadap word of mouth mahasiswa STAHN Gde Pudja Mataram.

\section{B. TELAAH PUSTAKA}

\section{Kualitas layanan}

Parasuraman, et al., (1988) mendefinisikan kualitas layanan merupakan refleksi persepsi evaluatif konsumen terhadap layanan yang diterima pada suatu waktu tertentu. Selanjutnya, Cronin dan Taylor, (1992) menambahkan service performance sebagai sarana untuk mengukur kualitas layanan. Service performance lebih bisa menjawab permasalahan yang muncul dalam menentukan kualitas jasa. Hal ini dikarenakan bagaimanapun konsumen hanya akan bisa menilai kualitas yang mereka terima dari suatu produsen tertentu bukan pada persepsi mereka atas kualitas jasa pada umumnya. Service performance dioperasionalkan menurut model service quality Parasuraman, et al., (1988) dengan menggunakan lima dimensi service quality, tetapi tidak menggunakan skala persepsi - harapan (Dharmayanti, 2006).

Skala dalam instrumen dalam servperf adalah bagian persepsi dari instrumen servqual, telah membuktikan suatu konsep pengukuran yang lebih valid terhadap kualitas layanan, karena validitas dan bukti validitas diskriminannya (Marbun dan Suardhika, 2013). Empat model diuji dalam penelitian tersebut, yaitu:

1. $\mathrm{SQ}=($ Performance-Expectation $)$,

2. $S Q=$ Importance, $($ Performance-Expectation $)$,

3. $S Q=($ Performance $)=S E R V P E R F$,

4. $S Q=$ Importance, $($ Performance).

Hasil pengujian menunjukkan model yang ketiga yaitu $\mathrm{SQ}=($ Performance $)=$ servperf memiliki indeks kesesuaian model yang terbaik dan mampu menjelaskan lebih banyak varians. Dengan demikian, mereka menyimpulkan bahwa instrumen terbaik yang dapat digunakan dalam mengukur kualitas layanan adalah berdasarkan kinerja saja, yaitu komponen persepsi 
dari instrumen servqual (Marbun dan Suardhika, 2013). Karena kualitas layanan diukur berdasarkan kinerja jasa dari penyedia jasa, maka instrumen yang mereka usulkan dinamakan servperf (Service Performance).

Kualitas layanan yang positif dari lembaga pendidikan memberikan dampak terhadap keinginan seseorang untuk merekomendasikan lembaga tersebut kepada orang lain (Leonnard and Thung, 2017). Keinginan tersebut muncul setelah seseorang memperoleh kesan dan pengalaman yang positif saat mengeyam pendidikan dilembaga tersebut. Word of mouth positif yang disampaikan akan memberikan dampak munculnya calon pelanggan yang potensial untuk menikmati kualitas layanan yang didengarnya. Sebaliknya, kualitas layanan negatif yang diterima maka akan berdampak pada word of mouth negatif.

Variabel kualitas layanan adalah keseluruhan kesan yang diterima mahasiswa STAHN Gde Pudja Mataram menyangkut layanan yang diberikan. Adapun indikator kualitas layanan adalah sebagai berikut: bukti fisik (tangible), keandalan (reliable), daya tanggap (responsiveness), jaminan (assurance), empati (empathy).

\section{Citra Lembaga}

Pada umumnya citra dapat diartikan sebagai seperangkat keyakinan, ide, dan kesan yang dimiliki terhadap suatu obyek. Citra lembaga dapat direfleksikan sebagai persepsi pengguna layanan terhadap lembaga (Kotler dan Keller 2012). Citra lembaga berhubungan dengan fisik dan atribut yang menyangkut nama, bangunan, dan produk untuk mempengaruhi kualitas yang dikomunikasikan supaya tertarik dengan lembaga tersebut. Citra lembaga yang positif adalah salah satu cara untuk dapat menjalin dan memelihara hubungan yang baik antara lembaga dengan masyarakat umum.

Bagi suatu lembaga, citra yang baik mutlak diperlukan (Kotler dan Keller 2012). Membangun citra yang baik lembaga membutuhkan waktu yang panjang dan biaya yang besar. Citra dapat terbentuk melalui faktor komunikasi dan pengalaman konsumen selama memanfaatkan/mengkonsumsi barang dan jasa yang mereka konsumsi. Citra terbentuk melalui berbagai persepsi yang terdapat dalam benak konsumen terhadap suatu obyek dan pada akhirnya sangat mempengaruhi analisa dan suatu tindakan pengambilan keputusan.

Hubungan citra lembaga dengan word of mouth mencerminkan cerita positif tentang citra lembaga akan mampu membangun word of mouth positif tentang lembaga (Putra, et al., 2015). Konsumen yang menilai suatu lembaga dengan citra yang baik akan menceritakan hal positif tentang lembaga tersebut. Menurut Bayupratama (2017) menyatakan bahwa citra berpengaruh positif dan signifikan terhadap word of mouth pada nasabah Bank Mandiri di Surabaya. Sejalan 
dengan penelitian tersebut, Putra, et al., (2015) menemukan bahwa citra perusahaan berpengaruh positif dan signifikan terhadap word of mouth pada Bank BPD Bali di Denpasar.

Meningkatkan citra lembaga STAHN Gde Pudja melalui sosialisasi yang dilakukan lembaga sampai ke daerah terluar dan terpencil. Tujuannya adalah memperkenalkan STAHN Gde Pudja Mataram dan harapan calon mahasiswa mau memilih STAHN Gde Pudja Mataram sebagai pilihan pertama. Di sisi lain, STAHN Gde Pudja Mataram melakukan rebranding menjadi sekolah kewirausahaan dengan motto building excellent character. Rebranding dilakukan untuk mempersiapkan lulusan memiliki daya saing pada dunia kerja.

\section{Word of Mouth}

Menurut Kotler dan Keller (2012) word of mouth dapat menjadi metode promosi yang efektif. Dikatakan strategi pemasaran yang paling efektif karena komunikasi dari mulut ke mulut merupakan pengenalan dari konsumen yang sudah pernah menikmati kepuasan dari satu lembaga. Saluran komunikasi personal yang berupa ucapan atau perkataan dari mulut ke mulut yang dilakukan oleh konsumen merupakan media promosi yang efektif dan efisien bagi perusahaan. Pada umumnya, ucapan yang disampaikan dari konsumen, oleh konsumen, dan untuk konsumen adalah bentuk kepuasan konsumen yang diterima dari perusahaan. Word of mouth memiliki peranan penting dalam membentuk sikap dan perilaku konsumen (Putra, et al., 2015). Word of mouth diperoleh oleh konsumen melalui orang terdekat yang mereka percaya seperti saudara, teman, pendapat ahli ataupun masukan dari keluarga.

Word of mouth merupakan penyebarluasan opini pengguna jasa pendidikan secara massif kepada khalayak ramai. (Brown, et al., 2005) menyatakan bahwa word of mouth terjadi ketika pengguna jasa pendidikan menceritakan/berbicara kepada orang lain tentang nama, merk, layanan suatu lembaga. Putra, et al., (2015) menyatakan bahwa word of mouth adalah pesan tentang produk atau jasa dari suatu perusahaan atau tentang perusahaan itu sendiri, dalam bentuk komentar, kinerja produk, keramahan, kejujuran, kecepatan pelayanan dan hal lainnya yang dapat dirasakan dan didalami oleh seseorang yang disampaikan kepada orang lain. Dalam menyampaikan kesan dapat berupa kesan yang bersifat positif dan kesan yang bersifat negatif.

\section{Pengaruh Kualitas Layanan terhadap Word of Mouth}

Word of mouth memegang peranan penting dalam membentuk sikap dan perilaku pengguna jasa. Word of mouth 7 kali lebih efektif dibandingkan iklan di majalah dan koran, 4 kali lebih efektif dari personal selling serta 2 kali lebih efektif daripada iklan radio yang dilakukan oleh pemasar (Mahardika, et al., 2018). Kualitas jasa merupakan salah satu variabel yang dapat mempengaruhi word of mouth. Kualitas jasa secara positif berpengaruh terhadap 
kecenderungan pengguna jasa untuk melakukan word of mouth. Persepsi kualitas jasa perusahaan yang lebih tinggi daripada harapan konsumen, akan menciptakan suatu word of mouth yang positif. Namun, jika kualitas jasa yang ditawarkan lebih rendah daripada harapan pengguna jasa, maka pengguna jasa tersebut akan memberikan rekomendasi atau word of mouth negatif. Penelitian yang dilakukan oleh Saktiani (2015) menyatakan bahwa kualitas layanan berpengaruh positif dan signifikan terhadap word of mouth pada Politeknik Negeri Malang. Sejalan dengan hasil penelitian tersebut menurut Anita dan Rahanatha (2015) menyatakan bahwa kualitas layanan secara langsung maupun tidak langsung berpengaruh positif dan signifikan terhadap word of mouth pada PT. Sarana Dewata Courir.

\section{Pengaruh Citra Lembaga terhadap Word of Mouth}

Citra lembaga dianggap sebagai aset yang memberikan kesempatan organisasi untuk membedakan dirinya dengan pesaing dan bertujuan untuk memaksimalkan pangsa pasar, meningkatkan keuntungan, menarik pelanggan baru, serta mempertahankan pelanggan yang sudah ada, menetralkan tindakan pesaing dan kelangsungan hidup organisasi. Hal ini dikarenakan citra yang baik membantu mengurangi ketidakpastian dalam membuat keputusan pembelian dan memberikan pengetahuan konsumen terhadap produk atau jasa yang ditawarkan oleh lembaga. Semakin baik citra lembaga maka pengguna jasa akan bersedia untuk menceritakan dan merekomendasikan pengalamannya kepada pengguna jasa baru. Hasil penelitian Saktiani (2015) juga menyatakan bahwa citra berpengaruh positif dan signifikan terhadap word of mouth. Hasil penelitian tersebut juga didukung dengan hasil penelitian dari Putra, et al., (2015) yang menyatakan semakin baik citra perusahaan maka mampu meningkatkan word of mouth positif pada Bank BPD Bali.

Berdasarkan kerangka konseptual dapat diuraikan bahwa untuk meningkatkan word of mouth mahasiswa, Pihak STAHN Gde Pudja Mataram wajib meningkatkan kualitas layanan yang diberikan dan selalu membangun citra positif lembaga, yang selanjutnya dapat menciptakan word of mouth positif mahasiswa. Dengan demikian dapat disusun hipotesis penelitian sebagai berikut:

$\mathrm{H}_{1} \quad$ : Kualitas layanan berpengaruh positif dan signifikan terhadap word of mouth

$\mathrm{H}_{2}$ : Citra lembaga berpengaruh positif dan signifikan terhadap word of mouth 


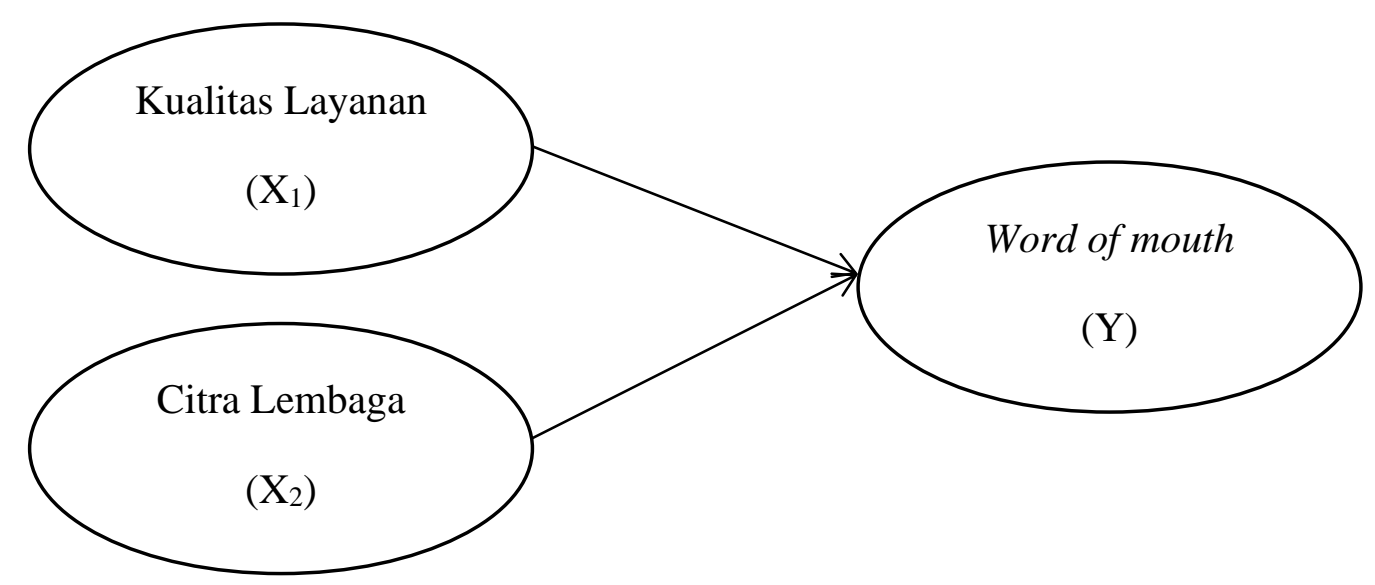

Gambar 1. Kerangka Konseptual

\section{METODE PENELITIAN}

Penelitian ini tergolong dalam penelitian eksplanatori yaitu rancangan penelitian pengujian hipotesis dan kausalitas. Penelitian ini dilaksanakan di STAHN Gde Pudja Mataram dengan obyek penelitian adalah mahasiswa. STAHN Gde Pudja Mataram dipilih sebagai lokasi penelitian karena satu-satunya lembaga pendidikan tinggi keagamaan Hindu di Kota Mataram dibawah naungan Kementerian Agama.

Penelitian ini menggunakan data yang bersumber dari data primer dengan pengumpulan kuesioner. Populasi adalah mahasiswa STAHN Gde Pudja Mataram pada semester gasal tahun akademik 2019/2020 berjumlah 532 dengan tingkat signifikansi 10\%, dihitung menggunakan rumus slovin banyaknya sampel sejumlah 84 mahasiswa. Adapun instrumen pengumpulan data menggunakan skala likert 1-5 dimana sangat tidak setuju (1), tidak setuju (2), ragu-ragu (3), setuju (4), dan sangat setuju (5). Data dikumpulkan menggunakan teknik sampling accidental random sampling. Secara teknis analisis data yang digunakan dikelompokkan menjadi dua yaitu analisis deskriptif dan analisis statistik inferensial (Sugiyono 2014), alat analisis yang digunakan dalam penelitian ini adalah SPSS versi 23.

\section{HASIL DAN PEMBAHASAN}

\section{Uji Karakteristik Responden}

Analisis ini digunakan untuk mengetahui prosentase responden berdasarkan karakteristik demografi. Data di tabel 1 menunjukan bahwa karakteristik responden terbagi atas jenis kelamin, usia, dan semester. Jika berdasarkan jenis kelamin maka responden terbanyak adalah perempuan dengan $61,90 \%$ dan responden laki-laki dengan 39,10\%. Responden berdasar usia 18-20 tahun sebanyak 63,10\% dan diatas 20 tahun sebanyak 36,90\%. Berdasarkan semester 
berturut-turut dari semester tiga sebanyak $60,71 \%$, semester satu $19,05 \%$, semester lima dengan $16,67 \%$ dan semester tujuh dengan $3,57 \%$. Seluruh responden tersebar dimasingmasing program studi $\mathrm{S} 1$.

Tabel 1. Karakteristik Responden

\begin{tabular}{|l|l|r|r|}
\hline Karakteristik & Keterangan & Jumlah & Persen (\%) \\
\hline \multirow{3}{*}{ Jenis Kelamin } & Laki & 32 & 38,10 \\
& Perempuan & 52 & 61,90 \\
\cline { 2 - 4 } & Total & 84 & 100 \\
\hline \multirow{3}{*}{ Usia } & $<18$ & 0 & 0 \\
& $18-20$ & 53 & 63,10 \\
& $>20$ & 31 & 36,90 \\
\cline { 2 - 4 } & Total & 84 & 100 \\
\hline \multirow{5}{*}{ Semester } & Satu & 16 & 19,05 \\
& Tiga & 51 & 60,71 \\
& Lima & 14 & 16,67 \\
& Tujuh & 3 & 3,57 \\
\cline { 2 - 4 } & Total & 84 & 100 \\
\hline
\end{tabular}

Sumber : Pengolahan data primer (2020)

\section{Hasil Uji Validitas dan Reliabilitas}

Hasil uji validitas menunjukan nilai KMO 0,651, hasil ini menunjukan bahwa intrumen kualitas layanan dan citra lembaga valid untuk menguji variable word of mouth karena nilai 0,651 lebih besar dari 0,5 yang merupakan standar nilai uji validitas. Uji reliabilitas menunjukan nilai cronbach alpha sebesar 0,712, hasil ini berarti bahwa seluruh instrument penelitian reliabel yang ditunjukan dengan nilai 0,712>0,6.

\section{Hasil Uji Asumsi Klasik}

Uji asumsi klasik yang dilakukan meliputi uji multikolonieritas, uji heterokedastisitas, autokorelasi dan normalitas. Adapun hasil pengujian dijabarkan pada tabel 2 sebagai berikut.

Tabel 2. Hasil Uji Asumsi Klasik

\begin{tabular}{|l|l|l|}
\hline \multicolumn{1}{|c|}{ Uji } & \multicolumn{1}{c|}{ Hasil } & \multicolumn{1}{c|}{ Kesimpulan } \\
\hline Multikolonieritas & $\begin{array}{l}\text { Tolerance }>0,1 \\
\text { VIF }<10\end{array}$ & Lolos pengujian \\
\hline Heterokedastisitas & $\mathrm{p}>0,05$ & Lolos pengujian \\
\hline Autokorelasi & $\mathrm{p}>0,05$ & Lolos pengujian \\
\hline Normalitas & $\mathrm{p}>0,05$ & Lolos pengujian \\
\hline
\end{tabular}

Sumber: hasil analisis SPSS 23.

\section{Uji t}

Tahap analisis data menggunakan analisis regresi dapat dilihat pada tabel 3. Hasil uji t yang dilakukan menunjukan bahwa hubungan antara kualitas layanan terhadap word of mouth dapat dilihat dari nilai signifikansi sebesar 0,142 dengan nilai t-statistik sebesar 1,482. Nilai t- 
statistik tersebut berada dibawah nilai kritis 1,96. Dengan demikian dapat dinyatakan bahwa kualitas layanan yang diberikan ternyata tidak mampu mempengaruhi word of mouth mahasiswa STAHN Gde Pudja Mataram secara langsung. Kualitas layanan pada STAHN Gde Pudja Mataram yang diukur dengan indikator bukti fisik, daya tanggap, keamanan, empati dan keandalan belum mampu memberikan kepuasan kepada mahasiswa.

Tabel 3. Hasil Uji t Kualitas Layanan dan Citra Lembaga Terhadap Word of Mouth

\section{Coefficients $^{\text {a }}$}

\begin{tabular}{|c|c|c|c|c|c|}
\hline \multirow[b]{2}{*}{ Model } & \multicolumn{2}{|c|}{$\begin{array}{c}\text { Unstandardized } \\
\text { Coefficients }\end{array}$} & \multirow{2}{*}{$\begin{array}{c}\text { Standardized } \\
\text { Coefficients } \\
\text { Beta }\end{array}$} & \multirow[b]{2}{*}{$\mathrm{T}$} & \multirow[b]{2}{*}{ Sig. } \\
\hline & $\mathrm{B}$ & Std. Error & & & \\
\hline 1 (Constant) & 2,350 & ,446 & & 5,266 &, 000 \\
\hline Kualitas_Layanan &, 178 &, 120 & , 173 & 1,482 &, 142 \\
\hline Citra_Lembaga & ,315 &, 104 & ,353 & 3,018 & ,003 \\
\hline
\end{tabular}

a. Dependent Variable: WOM

Sumber: hasil analisis SPSS 23.

Kualitas layanan yang diberikan tidak terdapat ciri khas atau keunikan yang mengakibatkan mahasiswa tidak berkeinginan untuk menceritakan dan merekomendasikan STAHN Gde Pudja Mataram kepada orang lain. Temuan ini sejalan dengan hasil penelitian (Saputro 2012) yang menyatakan bahwa kualitas pelayanan berpengaruh negatif dan tidak signifikan terhadap word of mouth pada restoran Suka Sambal Food Court Grand Mall Solo.

Di samping itu, hasil uji t juga menunjukkan bahwa citra lembaga berpengaruh positif dan signifikan terhadap word of mouth. Hasil uji terhadap koefisien parameter antara citra lembaga terhadap word of mouth menunjukkan adanya hubungan yang positif dengan nilai koefisien sebesar 0,315 dengan nilai t statistik sebesar 3,018. Nilai t statistik tersebut berada diatas nilai kritis 1,96 . Dengan demikian dapat dinyatakan bahwa citra lembaga yang diberikan mampu mempengaruhi word of mouth mahasiswa STAHN Gde Pudja Mataram secara langsung.

Citra positif lembaga yang melekat dengan sangat kuat pada diri mahasiswa memberikan nilai positif bagi mahasiswa STAHN Gde Pudja Mataram untuk mempertahankan citra lembaga. Dengan tercapainya nilai tersebut mahasiswa semakin yakin dan percaya untuk menempuh pendidikan di STAHN Gde Pudja Mataram. Keyakinan dan kepercayaan ini yang menghantarkan mahasiswa untuk menceritakan pengalamannya selama menempuh pendidikan. Selanjutnya, lebih jauh mahasiswa mau merekomendasikan STAHN Gde Pudja Mataram kepada teman-temannya untuk menempuh pendidikan di STAHN Gde Pudja Matam. Citra positif lembaga merupakan keuntungan jangka panjang bagi lembaga. Citra lembaga 
merupakan pemegang peranan sentral dalam memenangkan persaingan dengan lembaga pendidikan lainnya. Hasil temuan ini sejalan dengan hasil penelitian Saktiani (2015) yang menyatakan bahwa citra institusi berpengaruh positif dan signifikan pada Politeknik Negeri Malang.

\section{E. KESIMPULAN}

Berdasarkan pengujian yang dilakukan dapat disimpulkan bahwa kualitas layanan berpengaruh positif, tetapi tidak signifikan terhadap word of mouth mahasiswa STAHN Gde Pudja Mataram. Berarti bahwa semakin baik kualitas pelayanan yang diberikan belum mampu meningkatkan word of mouth mahasiswa STAHN Gde Pudja Mataram. Hal ini dikarenakan kualitas layanan yang diberikan belum mampu memberikan kepuasan atas ekspektasi mahasiswa terhadap layanan STAHN Gde Pudja Mataram. Citra lembaga berpengaruh positif dan signifikan terhadap word of mouth. Dapat diartikan bahwa semakin baik citra lembaga maka mahasiswa STAHN Gde Pudja Mataram semakin aktif dalam merekomendasikan atau word of mouth STAHN Gde Pudja Mataram kepada teman-temannya. Dengan kata lain, semakin baik citra kampus maka mahasiswa akan semakin sering menceritakan hal-hal positif kepada temannya. Lebih lanjut mereka mau merekomendasikan calon mahasiswa baru untuk menempuh pendidikan pada STAHN Gde Pudja Mataram.

Berdasarkan hasil temuan dan pembahasan terlihat bahwa responden merasa kurang puas terhadap layanan yang diberikan oleh STAHN Gde Pudja Mataram. Ketidakpuasan responden terhadap kualitas layanan dapat terlihat dari kelima indikator kualitas layanan yakni bukti fisik (tangible), keandalan (reliable), daya tanggap (responsiveness), jaminan (assurance), empati (empathy) memperoleh penilaian kurang baik dari responden. Maka dari itu, lembaga diharapkan terus meningkatkan kualitas layanan agar dapat memenuhi ekspektasi pengguna jasa. Perbaikan kualitas layanan dilakukan secara kontinyu baik dari infrastuktur dan pemberian layanan prima.

Dalam rangka meningkatkan word of mouth dapat dilakukan dengan terus berbenah dalam memberikan layanan yang berkualitas, meningkatkan citra lembaga, serta melakukan sosialisasi. Sosialisasi dilakukan dalam rangka mengenalkan STAHN Gde Pudja kepada masyarakat. Mereposisi diri dengan motto "building excellent character" sehingga memiliki nilai baru dimasyarakat.

Bagi penelitian mendatang dapat mereplikasi model penelitian ini melalui model pendekatan longitudinal (dari waktu ke waktu), dan memungkinkan digunakan pada lembaga 
lainnya. Selain itu peneliti mendatang dapat memodifikasi model penelitian dengan menambahkan dan mengembangkan indikator maupun variabel lain. Hal ini didasari bahwa variabel kualitas pelayanan, citra dan word of mouth cukup banyak dan berbeda dengan kondisi satu sama lainnya.

\section{DAFTAR PUSTAKA}

Anita, Ni Luh Nyoman Yuni, and Gede Bayu Rahanatha. 2015. Pengaruh Kualitas Pelayanan Terhadap WOM Melalui Kepuasan Pada PT. Sarana Dewata Courier. E-Jurnal Manajemen, 4(2), 45.

Bayupratama, Chandra. 2017. Pengaruh Citra Bank Dan Kepercayaan Terhadap Keputusan Menabung Dengan Variabel Mediasi Word Of Mouth Pada Nasabah Bank Mandiri Di Surabaya. ABA Journal, 102(4), 24-25.

Brown, T.J., Barry, T.E., Dacin, P.A. dan Gunst, R.F. 2005. Spreading the Word: Investigating Antecedents of Consumers' Positive Word of Mouth Intentions and Behaviors in a Retailing Context. Journal of the Academy of Marketing Science, 33(2), 123-38.

Cronin, J.J., Jr and S.A. Taylor, 1992. Measuring Service Quality: A Reexamination and Extension. Journal of Marketing, 56, 53-68.

Dharmayanti, D. 2006. Analisis Dampak Service Performance dan Kepuasan Sebagai Moderating Variable Terhadap Loyalitas Nasabah (Studi pada Nasabah Tabungan Bank Mandiri Cabang Surabaya). Jurnal Manajemen Pemasaran, 1(1), 35-43.

Kotler, P., Kevin Lance Keller. 2012. Marketing Management 14th edition. Jakarta: PT. Indeks Kelompok Gramedia.

Leonnard, and Feby Thung. 2017. The Relationship of Service Quality, Word-Of-Mouth, And Repurchase Intention in Online Transportation Services. Journal of Process Management. New Technologies, 5(4), 30-40.

Mahardika, I Made Ngurah Oka, I Nengah Suardhika, and I Nengah Landra. 2018. Determination Loyalty Based on Service Quality, Customer Satisfaction and Trust at Pt. Bpr Bukit Tanjung Badung. International Journal of Contemporary Research and Review, 9(2), 20473-84.

Marbun, Saortua, I Nengah Suardhika. 2013. Pengaruh Service Performance Terhadap Nilai Institusi Dan Kepuasan Mahasiswa (Studi Pada Stipar Triatma Jaya). Jurnal Manajemen \& Akuntansi STIE Triatma Mulya, 19(1), 52-72

Nuryanto, Yulius Jatmiko. 2012. Kualitas Layanan Dan Positive Word of Mouth. Jurnal Dinamika Manajemen, 3(2), 148-54.

Parasuraman, A., Zeithaml, V.A., and Berry, L. 1988. SERQUAL: Multiple-item scale for Measuring Consumer Perceptions of Service Quality. Journal of Retailing, 64(1), 12 40. 
Putra, I Putu Danika Angga, Ni Nyoman Keti Yasa, and I Putu Gde Sukaatmaja. 2015. Pengaruh Citra Perusahaan Terhadap Wom Dan Loyalitas Nasabah. Forum Manajemen STIMI Handayani Denpasar, 13, 1-12.

Saktiani, Garnis Anggi. 2015. Pengaruh Kualitas Layanan Dan Citra Perusahaan Terhadap Kepuasan Pelanggan Dan Word of Mouth. JISIP: Jurnal Ilmu Sosial dan Ilmu Politik, 4(2), 342-53.

Saputro, Fransiskus Satrio. 2012. Pengaruh Kualitas Layanan Terhadap Word of Mouth Dan Minat Beli Kembali Dengan Kepuasan Pelanggan Sebagai Variabel Pemediasi. digilib.uns.ac.id.

Sriwidodo, Untung, and Ernawati. 2014. Pengaruh Citra Pasar Jum'at Karanganyar Terhadap Words of Mouth (WOM) Melalui Customer Delight Sebagai Variabel Mediasi. INFORMATIKA, 1(2), 39-52.

Sugiyono. 2014. Metode Penelitian Kuantitatif Kualitatif dan R\&D. Bandung: Alfabeta.

Ye, Ren, Desmond Lam, and Alvin Lee. 2011. “An Examination of Service Quality Dimensionality and Positive Word-Of-Mouth Intentions in a Chinese Telecommunication Context." 